\title{
Effects of blackcurrant-based juice on atherosclerosis-related biomarkers in cultured macrophages and in human subjects after consumption of a high-energy meal
}

\author{
Patricia Huebbe ${ }^{1}$, Katrin Giller ${ }^{1}$, Sonia de Pascual-Teresa ${ }^{2}$, Anne Arkenau ${ }^{3}$, Berit Adolphi ${ }^{4}$, \\ Sebastian Portius ${ }^{4}$, Cord N. Arkenau ${ }^{3}$ and Gerald Rimbach ${ }^{1 *}$ \\ ${ }^{1}$ Institute of Human Nutrition and Food Science, Christian-Albrechts-University of Kiel, Hermann-Rodewald-Straße 6, \\ D-24118 Kiel, Germany \\ ${ }^{2}$ Department of Metabolism and Nutrition, Instituto de Ciencia y Tecnologica de Alimentos y Nutricion, Consejo Superior \\ de Investigaciones Cientificas, E-28040 Madrid, Spain \\ ${ }^{3}$ Health Care Centre at Duck Pond, Kopperpahler Allee 121, D-24119 Kronshagen, Germany \\ ${ }^{4}$ Schwartauer Werke GmbH \& Co.KGaA, Lübecker Straße 49-55, D-23611 Bad Schwartau, Germany
}

(Submitted 5 April 2011 - Final revision received 18 August 2011 - Accepted 16 September 2011 - First published online 20 October 2011)

\begin{abstract}
Regular consumption of fruit and vegetables may be associated with decreased CVD risk. In the present study, we investigated the effects of blackcurrant (BC) juice, rich in polyphenols and ascorbic acid, on oxidative and inflammatory biomarkers in cultured macrophages in vitro and in human subjects with an atherosclerosis-prone phenotype (after consumption of a high-energy meal). In cultured macrophages (RAW264.7), BC treatment significantly inhibited lipopolysaccharide-induced inflammation as indicated by lower mRNA levels of TNF- $\alpha$, IL-1 $\beta$ and inducible NO synthase (iNOS) and lower nuclear p65 levels indicating decreased NF- $\mathrm{kB}$ activity. iNOS protein levels were lower and haem oxygenase 1 levels higher in BC-treated cells when compared with untreated controls. Subjects given a high-energy meal had elevated serum glucose and insulin levels with no significant difference between the BC-based juice and placebo treatment groups. TAG following meal ingestion tended to be attenuated after the BC treatment. Plasma ascorbic acid and radical-scavenging capacity were decreased following placebo meal consumption; however, BC significantly elevated both parameters compared with baseline and placebo ingestion. Plasma oxidised LDL, $\alpha$-tocopherol and paraoxonase activity were unchanged in both treatment groups. Furthermore, production of TNF- $\alpha$ and IL- $1 \beta$ was not significantly changed by BC meal consumption. The present results suggest potential antioxidative and anti-inflammatory properties of $\mathrm{BC}$ in vitro in cultured macrophages. Although the observations were not directly transferable to a postprandial in vivo situation, the present results show that BC juice consumption may improve postprandial antioxidant status as indicated by higher ascorbic acid levels and free radical-scavenging capacity in plasma.
\end{abstract}

Key words: Polyphenolic compounds: Ascorbic acid: Pro-inflammatory cytokines: Postprandial state

CVD is the leading cause of premature death in Western populations. Oxidative modification of LDL is considered to be a major trigger of atherosclerosis ${ }^{(1)}$. Furthermore, there is increasing experimental evidence that inflammatory processes play a central role in the aetiology and progression of atherosclerosis $^{(2)}$. Atherosclerotic modifications of the artery wall are dependent on both lifestyle and nutrition-related factors. Epidemiological and prospective studies support an inverse relationship between CVD and fruit and vegetable consumption $^{(3-6)}$. Despite the scarcity of clinical studies investigating the underlying mechanisms, beneficial effects of fruit and vegetables have often been attributed to the bioactive compounds within them, such as antioxidant vitamins and polyphenols. Studies in cultured cells and laboratory mice have demonstrated that the compounds in fruit and vegetables have diverse actions including antioxidant, anti-inflammatory and gene-regulatory properties ${ }^{(7-11)}$. Recent studies have suggested that fruit and vegetables potentially modify postprandial progression of oxidation and inflammation as evidenced by oxidative and inflammatory biomarkers. The postprandial state, particularly after a meal rich in fat and carbohydrates, is associated with a sharp increase in blood glucose, TAG, oxidative stress and inflammation ${ }^{(12)}$. Interestingly, the concomitant intake of orange juice and strawberries

Abbreviations: BC, blackcurrant; iNOS, inducible NO synthase; LPS, lipopolysaccharide; ORAC, Oxygen radical absorbance capacity; oxLDL, Oxidised LDL; PON, paraoxonase. 
has recently been shown to attenuate postprandial oxidative and inflammatory stress ${ }^{(13,14)}$.

Blackcurrant (BC) and other berry juices are particularly rich in vitamin $C$ and polyphenols including anthocyanins ${ }^{(15,16)}$. In the present study, we investigated the effects of $\mathrm{BC}$ on oxidative and inflammatory biomarkers in cultured macrophages (as a model for postprandial increased inflammation) and in human subjects with an atherosclerosis-prone phenotype after consumption of a high-energy meal.

\section{Materials and methods \\ In vitro analyses of fruit juice concentrates}

Fruit juice concentrates (BC, red grape, cherry and raspberry) were provided by Schwartauer Werke (Bad Schwartau, Germany). Fruit juices were diluted $(1: 4, \mathrm{w} / \mathrm{w})$ with methanol and centrifuged $\left(11000 \mathrm{~g}, 10 \mathrm{~min}\right.$, at $\left.4^{\circ} \mathrm{C}\right)$. Supernatants were used for the analysis of their in vitro antioxidative capacity and in cell-culture experiments. Final methanol concentration for all cell-culture experiments was $<0 \cdot 1 \%(\mathrm{v} / \mathrm{v})$.

Radical-scavenging capacity was measured using the oxygen radical absorbance capacity (ORAC) assay ${ }^{(17)}$. In brief, peroxyl radicals were generated by 2,2 '-azobis(2-amidinopropan), incubated with sodium fluorescein, and fluorescence measured at 485/520 nm (excitation/emission) every $1 \mathrm{~min}$ for $50 \mathrm{~min}$. Trolox served as reference and ORAC values were calculated by area under the curve of time-dependent changes in fluorescence. Results were related to $1 \mu \mathrm{mol} / 1$ of Trolox and are expressed as Trolox equivalents.

For quantification of ascorbic acid, fruit juice concentrates were diluted $(1: 2, \mathrm{w} / \mathrm{w})$ in $1.5 \%$ meta-phosphoric acid and then incubated with 2,5-diphenyl-3-thiazolyltetrazolium chloride. Absorbance was measured at $540 \mathrm{~nm}$. Ascorbic acid concentrations were calculated applying an external curve. Total polyphenolic content of fruit juices was measured using Folin-Ciocalteu's reagent, measuring absorbance at $720 \mathrm{~nm}$. Gallic acid was used as a reference.

Anthocyanin analyses were carried out using an Agilent Technologies 1200 Series liquid chromatograph with a quaternary pump and photodiode array detector (DAD). The HPLC system was equipped with a Phenomenex Aqua C18 column $(5 \mu \mathrm{m} ; 200 \AA$; $4.6 \times 150 \mathrm{~mm})$, which was set thermostatically at $35^{\circ} \mathrm{C}$. Solvents used were aqueous $4.5 \%$ formic acid (solvent $\mathrm{A}$ ) and HPLC-grade acetonitrile (solvent $\mathrm{B}$ ) at a flow rate of $0.5 \mathrm{ml} / \mathrm{min}$. Starting isocratically with $10 \% \mathrm{~B}$ up to $20 \mathrm{~min}$, the gradient was $13 \%$ B from 20 to $35 \mathrm{~min}, 15 \%$ $\mathrm{B}$ from 35 to $55 \mathrm{~min}, 35 \% \mathrm{~B}$ from 55 to $65 \mathrm{~min}$ and $10 \% \mathrm{~B}$ from 65 to $70 \mathrm{~min}$. Detection wavelengths were 280, 360 and
$520 \mathrm{~nm}$. Analyses were carried out in triplicate. Total anthocyanins in the juice were quantified at $520 \mathrm{~nm}$ by integrating all the peaks. The concentration of 3-monoglucosides of delphinidin, cyanidin and malvidin in the samples was determined using commercially available standards.

\section{Cell-culture experiments}

Murine macrophages (RAW264.7) were purchased from DSMZ (Braunschweig, Germany). Cell-culture medium and supplements were from PAA (Coelbe, Germany). Cells were grown in a humidified atmosphere at $37^{\circ} \mathrm{C}$ and $5 \% \mathrm{CO}_{2}$. RAW264.7 cells were incubated with test compounds (final concentration of fruit juices in cell-culture medium was $0 \cdot 2 \mathrm{mg} / \mathrm{ml}$ ) for $4 \mathrm{~h}$ followed by stimulation with $10 \mathrm{ng} / \mathrm{ml}$ of lipopolysaccharide (LPS; Sigma, Hamburg, Germany). Cells were harvested at indicated time points for the isolation of RNA and protein and for the quantification of cellular cholesterol concentration.

\section{mRNA expression}

For total RNA isolation, cells were lysed using TRIsure reagent (Bioline, Luckenwalde, Germany). Organic and aqueous phases were separated after chloroform addition and centrifugation, and RNA was precipitated with isopropanol. Total RNA concentration was quantified by measuring absorbance at $260 \mathrm{~nm}$ and RNA purity was controlled by calculating the ratio of $260 \mathrm{~nm} / 280 \mathrm{~nm}$ on a spectrophotometer (Beckman Coulter, Krefeld, Germany). One-step real-time RT-PCR analyses were performed, as described previously ${ }^{(18)}$, using the SensiMix ${ }^{\mathrm{TM}}$ One-Step Kit (Quantance, Bioline) on a Rotor Gene 6000 thermocycler (Corbett Research, Sydney, Australia). Primers (Table 1) were designed by Primer3 Input software (version 0.4.0). Relative mRNA levels of target genes were related to housekeeping gene expression.

\section{Protein levels}

For Western blotting, whole-cell homogenates and nuclear extracts were prepared as described previously ${ }^{(19)}$. Proteins were separated by SDS-PAGE and transferred onto a nitrocellulose membrane (Bio-Rad Laboratories, Munich, Germany). Target proteins were identified using respective primary and secondary antibodies (anti-haem oxygenase 1 (HO-1; Biomol, Hamburg, Germany), anti-inducible NO synthase (iNOS; Stressgen, Enzo Life Sciences, Loerrach, Germany), anti$\alpha$-tubulin, anti-p65, anti-actin, anti-TATA box binding protein

Table 1. Sequences of primers used for one-step real-time RT-PCR

\begin{tabular}{lll}
\hline & \multicolumn{1}{c}{ Forward } & \multicolumn{1}{c}{ Reverse } \\
\hline TNF- $\alpha$ & CATCTTCTCAAAATTCGAGTGACAA & TGGGAGTAGACAAGGTACAACCC \\
IL-1 $\beta$ & CAACCAACAAGTGATATTCTCCATG & GATCCACACTCTCCAGCTGCA \\
iNOS & GGCAGCCTGTGAGACCTTTG & GCATTGGAAGTGAAGGTTC \\
CD36 & CAAAACGACTGCAGGTCAAC & CCAATGGTCCCAGTCTCATT \\
GAPDH & CCGCATCTTCTTGTGCAGT & GGCAACAATCTCCACTTTGC
\end{tabular}

iNOS, inducible NO synthase; GAPDH, glyceraldehyde 3-phosphate dehydrogenase. 
(TBP) and all secondary antibodies (Santa Cruz Biotechnology, Heidelberg, Germany). Protein bands were visualised using the Pierce ${ }^{\circledR}$ ECL Western Blotting Substrate kit (Thermo Scientific, Schwerte, Germany).

\section{Cellular cholesterol}

For the determination of cellular cholesterol, cells were homogenised in potassium phosphate buffer and incubated with $20 \mathrm{mmol} / \mathrm{l}$ of sodium cholate in potassium phosphate buffer with $1 \%$ Triton X-100. Total cholesterol was determined by enzymatic conversion of cholesterol generating $\mathrm{H}_{2} \mathrm{O}_{2}$. Peroxidation of 4-hydroxyphenylacetate by $\mathrm{H}_{2} \mathrm{O}_{2}$ results in the formation of fluorescent 4-hydroxyphenylacetate-dimers (2,2'-dihydroxy-5,5'-dicarboxy-methyl-biphenyl). Fluorescence measured at $360 / 465 \mathrm{~nm}$ (excitation/emission) was directly proportional to total cholesterol content. Cellular cholesterol was quantified using an external cholesterol standard curve.

\section{Study subjects and study design}

Male study subjects were recruited from the local community according to the following inclusion criteria: BMI $25-35 \mathrm{~kg} / \mathrm{m}^{2}$, total cholesterol $>5.2 \mathrm{mmol} / \mathrm{l}$ and LDL-cholesterol $>3.6 \mathrm{mmol} / \mathrm{l}$. Exclusion criteria were diagnosed diabetes mellitus, history of cardiovascular events, regular intake of statins, occurrence of any chronic disease and smoking. The study was conducted according to the guidelines laid down in the Declaration of Helsinki, and the study protocol was approved by the ethics committee of the Medical Association, Bad Segeberg, Germany. Written informed consent was obtained from all subjects.

The study was performed using a single-blind, placebocontrolled, cross-over design. Each participant was given a high-energy meal in combination with (1) a BC-based fruit beverage (15\% BC purée, 9\% raspberry purée, 7\% cherry purée and 39\% red grape juice) or (2) a placebo beverage. Both beverages contained similar amounts of banana purée resulting in similar viscosity and texture. The high-energy meal served as a stimulus for postprandial changes in atherosclerosis-related biomarkers. The meal was composed of $200 \mathrm{~g}$ cream ( $30 \% \mathrm{fat}$ ), $75 \mathrm{~g}$ sucrose and $250 \mathrm{~g}$ BC or placebo beverage (Table 2). The $\mathrm{BC}$ and placebo beverages were identical in energy, sucrose, fructose and glucose, and adjusted for dietary fibre content. The BC and placebo beverages were different in ascorbic acid (122 $v$. $<1 \mathrm{mg} /$ $250 \mathrm{~g}$ ) and total polyphenol content (617 v. $41 \mathrm{mg}$ gallic acid equivalents $/ 250 \mathrm{~g}$ ). Overnight fasting blood samples were taken before ingestion of the test meal (assigned as $0 \mathrm{~min}$ ). After consumption of the respective test meals, venous blood was taken at consecutive time points (at 15, 30, 45, $60,90,120,150,180,210$ and $240 \mathrm{~min}$ following the test meal intake). Each participant was given the $\mathrm{BC}$ and placebo test meals at intervals of $6-7 \mathrm{~d}$.

\section{Blood analyses}

Blood samples were collected in heparinised syringes, and plasma, separated by centrifugation, was stored at $-80^{\circ} \mathrm{C}$
Table 2. Ingredients of the test meals composed of cream and sugar in combination with a blackcurrant (BC)-based or placebo beverage (placebo)

\begin{tabular}{lcc}
\hline & BC & Placebo \\
\hline Energy & & \\
kcal & 1030 & 1029 \\
kJ & 4310 & 4305 \\
Fat (g) & $63 \cdot 8$ & $63 \cdot 8$ \\
Protein (g) & $6 \cdot 1$ & $6 \cdot 0$ \\
Carbohydrates (g) & $107 \cdot 8$ & $107 \cdot 6$ \\
Dietary fibre (g) & $2 \cdot 5$ & $1 \cdot 8$ \\
Ascorbic acid (mg) & $122 \cdot 3$ & 0.3 \\
Polyphenolic compounds (mg) & 617 & 41 \\
Anthocyanins (mg) & $11 \cdot 2$ & nd \\
Delphidin-3-glucoside & $7 \cdot 5$ & - \\
Cyanidin-3-glucoside & $2 \cdot 9$ & - \\
$\quad$ Malvidin-3-glucoside & $0 \cdot 8$ & - \\
ORAC value (mmol/l TE) & $5 \cdot 2$ & $0 \cdot 1$ \\
\hline
\end{tabular}

nd, Not detected; ORAC, oxygen radical absorbance capacity; TE, Trolox equivalents.

until analysis. Plasma TAG and cholesterol content was analysed using standard methods by a local service biochemical laboratory (Dres. Ballies, Kiel, Germany). Only one subject was excluded from TAG analyses due to his especially high basal TAG level $(10.7 \mathrm{mmol} / \mathrm{l})$. Radical scavenging capacity (ORAC) of plasma was measured as described above. Plasma IL-6 concentration was measured using a quantitative sandwich enzyme immunoassay (R\&D, Wiesbaden, Germany), according to the manufacturer's protocols.

\section{Ascorbic acid and $\alpha$-tocopherol}

Plasma ascorbic acid was measured following precipitation with perchloric acid by HPLC using a LiChrospher 100 column $(125 \times 4 \mathrm{~mm}, \quad \mathrm{RP}-18,5 \mu \mathrm{m}$; Merck, Darmstadt, Germany). Ascorbic acid concentrations were analysed using a Jasco HPLC system (Jasco Corporation, Gross-Umstadt, Germany) with a UV detector set on $243 \mathrm{~nm}$ and $\mathrm{NaH}_{2} \mathrm{PO}_{4}$ ( $45 \mathrm{mmol} / \mathrm{l})$ as the mobile phase. An external standard curve was used. Plasma $\alpha$-tocopherol was measured using a Waters spherisorb ODS-2 column $(100 \times 4.6 \mathrm{~mm}, 3 \mu \mathrm{m})$ and methanol-water $(98: 2, \mathrm{w} / \mathrm{w})$ as the mobile phase. The concentration of $\alpha$-tocopherol was identified by fluorescence at $290 / 350 \mathrm{~nm}$ (excitation/emission) and calculated using an external $\alpha$-tocopherol standard curve.

\section{Anthocyanins and anthocyanin metabolites}

Plasma concentrations of anthocyanins and anthocyanin metabolites were determined using an Agilent 1100 series liquid chromatograph/mass-selective detector equipped with a quadrupole (G1946D) mass spectrometer (Agilent Technologies, Waldrom, Germany). After protein precipitation from plasma, anthocyanins and their metabolites were extracted with cold methanol and concentrated using a speed-Vac. The samples were then taken up in $0.2 \mathrm{ml}$ water-methanol $(1: 1, \mathrm{v} / \mathrm{v})$, vortexed and passed through a $4 \mathrm{~mm}$ polyvinylidene-difluoride $0.2 \mu \mathrm{m}$ syringe filter into vials for HPLC analysis. The liquid chromatographic system consisted of 
a quaternary pump (G1311A), online vacuum degasser, autosampler (G1313A) and thermostatic column compartment, connected in line to a DAD (G1315B) before the mass spectrometer. Separation was achieved with an ORBAX Eclipse XDB-C18, 4.6× 150 mm, $5 \mu \mathrm{m}$ (Agilent Technologies). Elution was performed with a gradient between $2.5 \%$ acetic acid in Milli-Q water (solution A), a mixture of $2.5 \%$ acetic acid in Milli-Q water-acetonitrile (90:10, solution B) and pure acetonitrile (solution $C$ ) at a flow rate of $0.5 \mathrm{ml} / \mathrm{min}$ and an injection volume of $20 \mu \mathrm{l}$ and an elution programme consisting of the following: from $100 \% \mathrm{~A}$ to $100 \% \mathrm{~B}$ in $3 \mathrm{~min}$, from $100 \%$ to $93 \% \mathrm{~B}$ in $5 \mathrm{~min}$, from $7 \%$ to $10 \% \mathrm{C}$ in $\mathrm{B}$ in $7 \mathrm{~min}$, from $10 \%$ to $15 \% \mathrm{C}$ in $5 \mathrm{~min}$, from $15 \%$ to $50 \%$ $\mathrm{C}$ in $5 \mathrm{~min}$ and isocratic $50 \% \mathrm{C}$ and $\mathrm{B}$ for another $5 \mathrm{~min}$. Electrospray ionisation in the positive ionisation mode was used. The electrospray capillary voltage was set to $2500 \mathrm{~V}$, with a nebulising gas flow rate of 12 litres $/ \mathrm{min}$ and a drying gas temperature of $150^{\circ} \mathrm{C}$. MS analyses were recorded in the single ion monitoring (SIM) mode at 493, 449 and $465 \mathrm{~m} / z$ for malvidin-3-glucoside, cyanidin-3-glucoside and delphinidin-3-glucoside, at 331, 287 and 303 for their respective aglycons, malvidin, cyanidin and delphinidin and at 507, 463 and 479 for their corresponding glucuronides. Full MS analyses were also recorded and from them the following ions $(\mathrm{m} / z)$ were extracted as post-analysis SIM in the positive mode at: 127, 171, 155, 169, 285, 139, 225 and 165 corresponding to 1,3,5-trihydroxybenzene (phloroglucinol), gallic acid, protocatechuic acid, vanillic acid, caffeic acid, hydroxybenzoic acid, sinapic acid and coumaric acid.

\section{Paraoxonase}

Paraoxonase (PON) activity in plasma was determined spectrophotometrically (Beckman Coulter) using phenylacetate as the substrate as described previously ${ }^{(20,21)}$. PON activity was related to HDL-concentration in plasma.

\section{TNF- $\alpha$ and IL-1 $\beta$}

For quantification of TNF- $\alpha$ and IL-1 $\beta$, whole blood was diluted $(1: 10, \mathrm{w} / \mathrm{w})$ in RPMI-1640 with $10 \%$ fetal bovine serum and cultured at standard conditions (see above). Whole-blood cultures were stimulated with LPS $(100 \mathrm{ng} / \mathrm{ml})$ and cell-culture supernatants were collected after $24 \mathrm{~h}$. Cytokine concentrations were determined using respective quantitative sandwich enzyme immunoassays (R\&D), according to the manufacturer's protocols.

\section{Statistical analysis}

Data are presented as means with their standard errors. mRNA expression results from cell-culture experiments were analysed by the $t$ test for independent samples and, in the absence of normal distribution, by the Mann-Whitney $U$ test. Since Western blotting is only a semi-quantitative measurement of protein levels, we did not apply statistical tests as far as the densitometric analysis of the Western blots is concerned. Data from the human study were analysed using paired $t$ tests (comparing results from the $\mathrm{BC} v$. placebo treatment or baseline $v$. postprandial changes). Differences were considered significant when $P<0 \cdot 05$. All statistical calculations were performed using SPSS version 15.0 (IBM, Ehningen, Germany).

\section{Results}

\section{In vitro analysis and cell-culture experiments}

Radical-scavenging capacity and concentrations of polyphenolic compounds and ascorbic acid were measured in juice concentrates of $\mathrm{BC}$, raspberry, cherry and red grape. $\mathrm{BC}$ and raspberry exhibited highest and second highest ORAC values, respectively. Furthermore, BC contained the highest levels of total polyphenols and ascorbic acid compared with raspberry, cherry and red grape (Table 3 ). Due to its relatively high levels of antioxidative compounds, BC was selected to systematically investigate its potential anti-inflammatory and anti-atherogenic effects in isolated cells.

At the mRNA level, pre-incubation of macrophages with BC significantly inhibited $(P<0 \cdot 001)$ LPS-induced expression of pro-inflammatory molecules such as TNF- $\alpha$, IL- $1 \beta$ and iNOS compared with cells treated only with LPS (Fig. 1(a)-(c)). Relative mRNA levels of the scavenger receptor CD36 were likewise reduced in BC-pre-treated cells compared with LPS (Fig. 1(d)). Since LPS stimulates inflammatory genes via $\mathrm{NF}-\kappa \mathrm{B}$ transactivation, nuclear levels of the NF- $\mathrm{B}$ subunit p65 were examined in the absence and presence of $\mathrm{BC}$. Incubation with BC significantly reduced LPS-induced nuclear translocation of p65 compared with control LPS-stimulated cells (Fig. 2). iNOS protein was up-regulated by concomitant LPS and interferon- $\gamma$ stimulation in our cells. Pre-incubation with BC almost completely abolished this iNOS up-regulation (Fig. 2). Furthermore, protein levels of the antioxidative haem oxygenase 1 were higher in BC-treated cells compared with untreated control cells.

Since accumulation of cholesterol in macrophages triggers foam-cell formation, cellular cholesterol levels were measured in the absence ( 43 (SEM 2) ng/mg) and presence (60 (SEM 4) $\mathrm{ng} / \mathrm{mg}$ ) of LPS. Under the conditions investigated, the $\mathrm{BC}$ treatment counteracted the LPS-induced increase in cellular cholesterol levels (37 (SEM 1) ng/mg).

\section{Human study}

A total of eleven male participants (37.4 (SEM 1.9) years, $32 \cdot 1(\operatorname{sem~} 1 \cdot 2) \mathrm{kg} / \mathrm{m}^{2}$ ) were included in the study (baseline

Table 3. Data of in vitro analyses of different fruit juice concentrates (Mean values with their standard errors)

\begin{tabular}{|c|c|c|c|c|c|c|}
\hline & \multicolumn{2}{|c|}{$\begin{array}{l}\text { ORAC value } \\
\text { (mmol/l TE) }\end{array}$} & \multicolumn{2}{|c|}{$\begin{array}{l}\text { Total polyphe- } \\
\text { nol content }(\mathrm{g} / \mathrm{l})\end{array}$} & \multicolumn{2}{|c|}{$\begin{array}{l}\text { Ascorbic } \\
\text { acid }(g / l)\end{array}$} \\
\hline & Mean & SEM & Mean & SEM & Mean & SEM \\
\hline Blackcurrant & 35.4 & $1 \cdot 1$ & $95 \cdot 9$ & 3.4 & $41 \cdot 8$ & 0.5 \\
\hline Raspberry & $11 \cdot 8$ & 1.4 & $42 \cdot 1$ & 0.4 & $5 \cdot 3$ & 0.2 \\
\hline Cherry & $6 \cdot 1$ & 0.7 & $26 \cdot 8$ & 0.2 & $3 \cdot 6$ & 0.1 \\
\hline Red grape & $5 \cdot 8$ & 0.8 & 8.9 & 0.1 & $3 \cdot 3$ & 0.1 \\
\hline Banana purée & 0.4 & 0.1 & $2 \cdot 0$ & 0.1 & 1.4 & 0.1 \\
\hline
\end{tabular}

$\mathrm{TE}$, Trolox equivalents. 

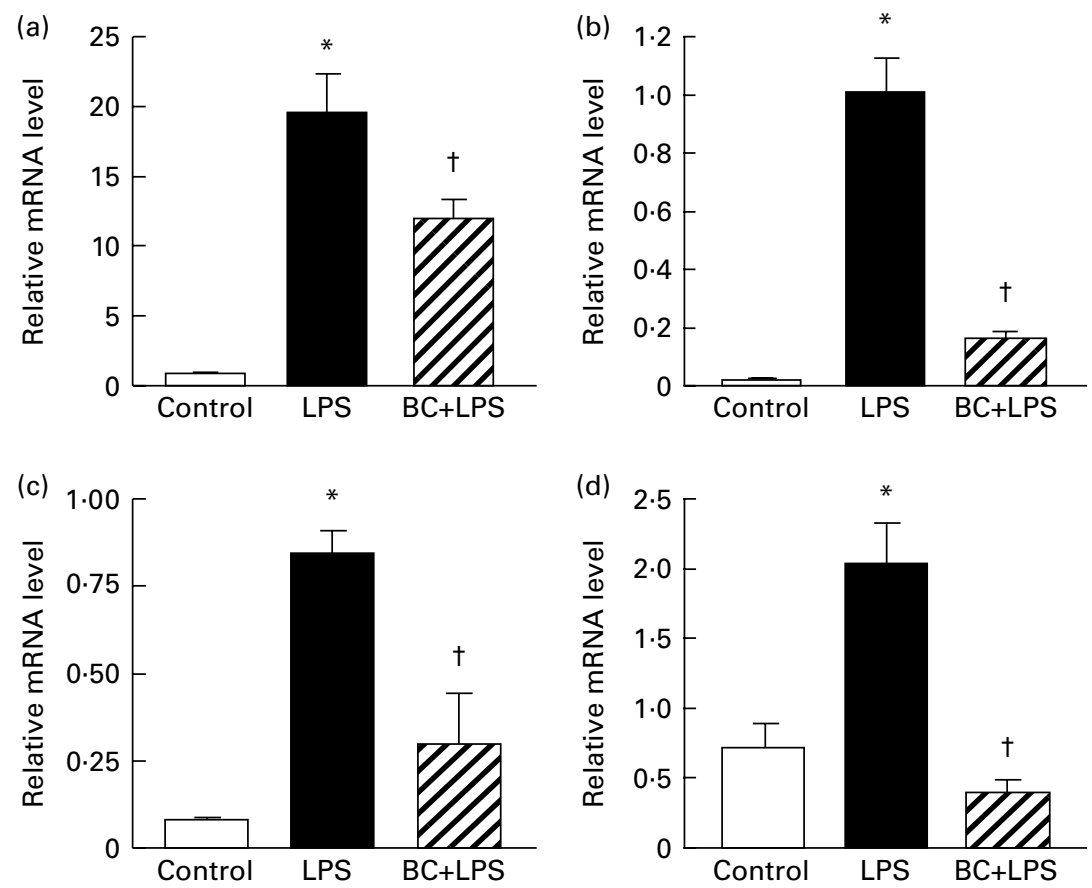

Fig. 1. Relative mRNA levels of inflammatory genes in RAW264.7 macrophages following incubation with blackcurrant (BC) fruit juice concentrate. Cells were pre-incubated with BC for $4 \mathrm{~h}$ and subsequently stimulated with lipopolysaccharide (LPS) for $1 \mathrm{~h}$ ((a) TNF- $\alpha$ ) or $6 \mathrm{~h}$ ((b) IL-1ß, (c) inducible NO synthase (iNOS) and (d) CD36). Untreated cells were used as control. Total RNA was isolated and relative mRNA levels were determined using real-time RT-PCR. Values are means, with standard errors represented by vertical bars $(n 4-8) .{ }^{*}$ Mean values were significantly different between the untreated (control) and LPS-treated cells (LPS; $P<0.05)$. † Mean values were significantly different between the BC pre-incubated LPS-treated cells $(\mathrm{BC}+\mathrm{LPS})$ and LPS $(P<0.05)$.

characteristics are summarised in Table 4). Plasma concentrations of cyanidin, delphinidin and malvidin were analysed after consumption of the BC-based test meal. However, neither anthocyanins in their glycosylated forms nor aglycones and glucuronides were detectable in plasma at any of the postprandial time points investigated. Plasma levels of other suggested anthocyanin metabolites were measured, including protocatechuic acid ${ }^{(22)}, P$-hydroxybenzoic acid and vanillic $\operatorname{acid}^{(23)}$, and also gut-derived metabolites such as 1,3,5-trihydroxybenzene ${ }^{(24)}$. Plasma levels of 1,3,5-trihydroxybenzene were increased from 71 (SEM 19) nmol/1 to 187 (SEM 41) nmol/ 130 min after consumption of the $\mathrm{BC}$ meal, decreasing to basal levels after $150 \mathrm{~min}$.

Postprandial changes in plasma glucose and insulin are shown in Fig. 3. Both parameters were increased at 15 and $30 \mathrm{~min}$ after ingestion of the test meals, although no
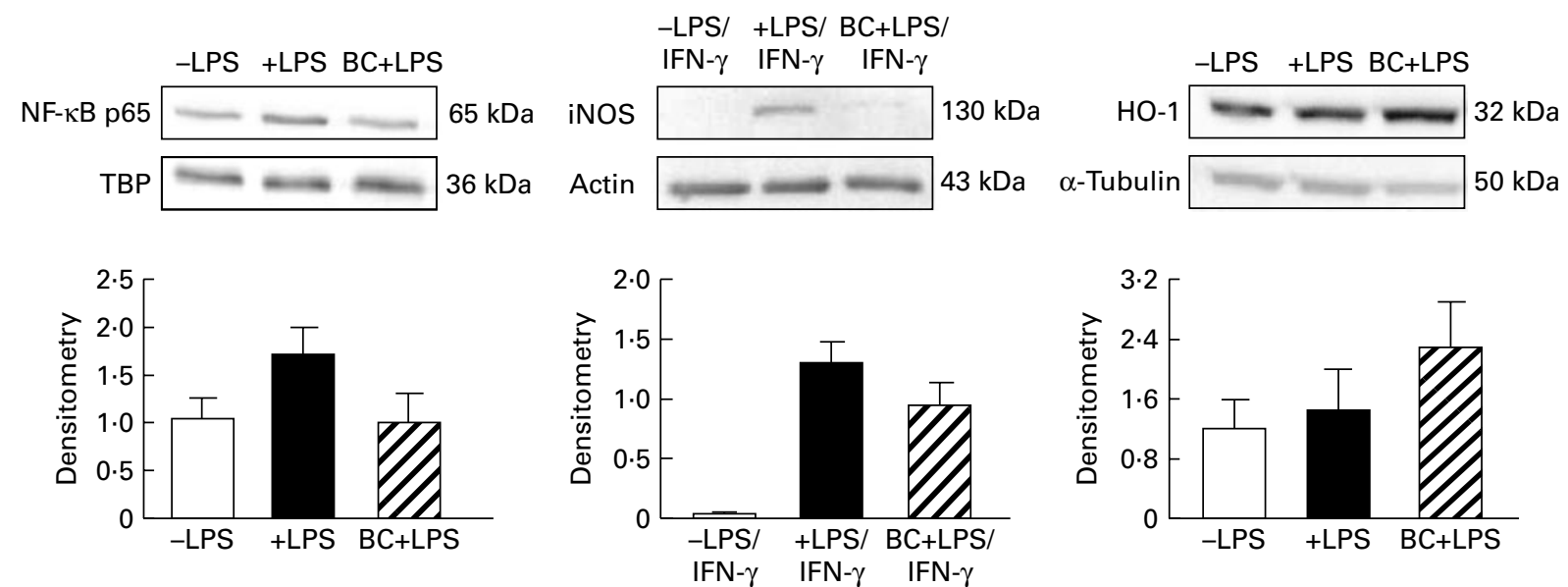

Fig. 2. Protein levels of NF-kB p65, haem oxygenase 1 (HO-1) and inducible NO synthase (iNOS) in RAW264.7 macrophages following incubation with blackcurrant $(\mathrm{BC})$ fruit juice concentrate. Cells were pre-incubated with $\mathrm{BC}$ for $24 \mathrm{~h}$ and subsequently stimulated with lipopolysaccharide (LPS) for $4 \mathrm{~h}$ (p65), $24 \mathrm{~h}$ (HO-1) or LPS in combination with interferon- $\gamma$ (IFN- $\gamma$ ) for $24 \mathrm{~h}$ (iNOS). Nuclear extracts (p65) or whole-cell lysates (iNOS and HO-1) were used for Western blotting analyses and one representative blot is shown, respectively. Densitometry was applied to relate target protein expression to loading controls. Values are means, with standard errors represented by vertical bars $(n 3-4)$. 
Table 4. Baseline characteristics and fasting blood parameters of male volunteers ( $n$ 11) participating in the human study

(Mean values with their standard errors)

\begin{tabular}{lcl}
\hline & Mean & SEM \\
\hline Age (years) & 37.4 & 1.9 \\
BMl $\left(\mathrm{kg} / \mathrm{m}^{2}\right)$ & 32.1 & 1.2 \\
Total cholesterol (mmol/l) & 6.04 & 0.37 \\
LDL-cholesterol (mmol/l) & 4.04 & 0.30 \\
HDL-cholesterol (mmol/l) & 1.09 & 0.08 \\
TAG (mmol/l) & 2.25 & 0.59 \\
Glucose (mmol/l) & 5.61 & 0.13 \\
Insulin (pmol/l) & 84.2 & 9.1 \\
\hline
\end{tabular}

differences were observed in peak concentrations between the $\mathrm{BC}$ and placebo treatments. At $30 \mathrm{~min}$ after both test meals, glucose and insulin levels declined. The rate of insulin decline tended to be faster after the placebo meal compared with the BC meal $\left(t_{\min }=65 v .131 \mathrm{~min}, P=0.082\right)$.

Plasma concentrations of TAG increased in response to the high-energy test meals, with maximal levels occurring at 171 and $144 \mathrm{~min}$ after both BC and placebo meals (Fig. 4(a)). After $240 \mathrm{~min}$, plasma TAG levels were still significantly increased compared with baseline $(P<0.001$ and $P=0.007$ for $\mathrm{BC}$ and placebo, respectively). No significant differences in postprandial TAG levels were observed between the $\mathrm{BC}$ and placebo groups, although there was a trend towards lower levels in the BC group $(P=0.059$ at $60 \mathrm{~min})$.

Postprandial changes in plasma radical-scavenging capacity (ORAC) and ascorbic acid are summarised in Fig. 4(b) and (c), respectively. After placebo consumption, ORAC values decreased over time from 2.4 at $0 \mathrm{~min}$ to $1.6 \mathrm{mmol} / 1$ Trolox equivalents at $240 \mathrm{~min}$, indicating a reduction in antioxidant capacity in response to the high-energy meal. In contrast, ORAC values declined in the first $60 \mathrm{~min}$ after the $\mathrm{BC}$ meal but then rose again to the initial level. ORAC values of the $\mathrm{BC}$ group were significantly higher compared with the placebo group after 90 and $120 \mathrm{~min}(P<0.040$ and $P<0.002)$. Also, plasma ascorbic acid concentrations were significantly elevated $120 \mathrm{~min}$ after meal consumption in BC-treated subjects compared with the placebo group $(P \leq 0.004)$; this elevation persisted until the last reading at $240 \mathrm{~min}$. Ascorbic acid levels increased from 39 to $53 \mathrm{mmol} / 1$ after consumption of the BC-rich juice.

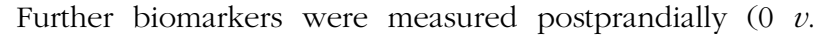
$240 \mathrm{~min}$ ) in plasma including total cholesterol, LDL- and HDL-cholesterol, oxidised LDL (oxLDL), $\alpha$-tocopherol and PON activity (Table 5). Total cholesterol, LDL and HDL levels were significantly lower following test meal consumption, though no differences were observed between the BC and placebo treatments.

Postprandial levels of oxLDL, $\alpha$-tocopherol and PON activity were not significantly different from basal levels and between the $\mathrm{BC}$ and placebo treatment groups. The production of TNF- $\alpha$ and IL- $1 \beta$ in response to LPS (measured in ex vivo whole-blood cultures) was significantly decreased in response to the placebo test meal. Interestingly, after consumption of the $\mathrm{BC}$ test meal, this decrease was not

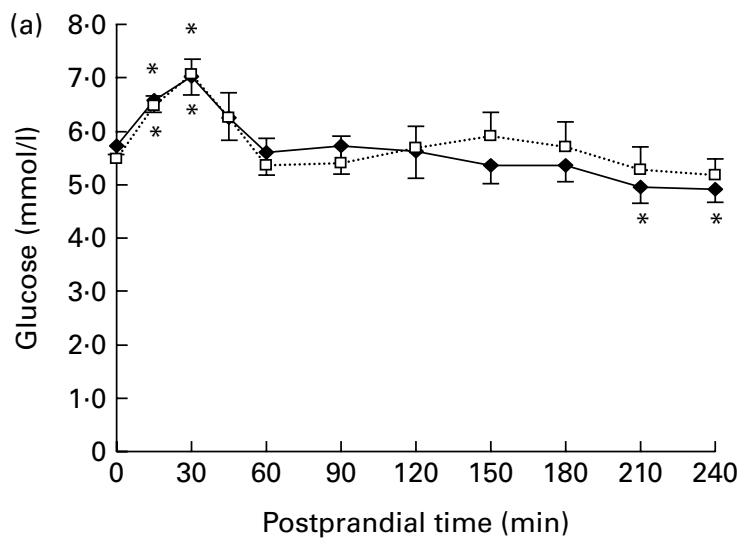

\begin{tabular}{lcccccc}
\hline & \multicolumn{3}{c}{ Blackcurrant } & & \multicolumn{3}{c}{ Placebo } & \\
\cline { 2 - 3 } & Mean & SEM & & Mean & SEM & $P$ \\
\hline$c_{\text {max }}(\mathrm{mmol} / \mathrm{l})$ & 7.5 & 0.1 & & 7.3 & 0.1 & 0.923 \\
$t_{\max }(\mathrm{min})$ & 55 & 4 & & 40 & 3 & 0.365 \\
$c_{\min }(\mathrm{mmol} / \mathrm{l})$ & 4.6 & 0.1 & 4.5 & 0.1 & 0.760 \\
$t_{\min }(\mathrm{min})$ & 127 & 7 & & 131 & 7 & 0.896 \\
AUC $_{(0-120)}(\mathrm{mmol} / \mathrm{I} \times \mathrm{min})$ & 722 & 46 & & 706 & 61 & 0.421 \\
AUC $_{(0-240)}(\mathrm{mmol} / \mathrm{I} \times \mathrm{min})$ & 1351 & 76 & & 1375 & 88 & 0.558 \\
\hline
\end{tabular}

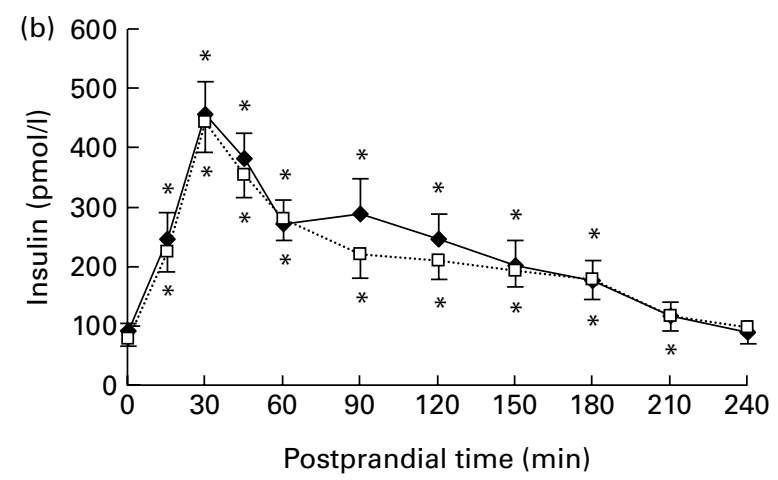

\begin{tabular}{lcccccc}
\hline & \multicolumn{3}{c}{ Blackcurrant } & & \multicolumn{3}{c}{ Placebo } & \\
\cline { 2 - 3 } & Mean & SEM & & Mean & SEM & $P$ \\
\hline$c_{\max }(\mathrm{mmol} / \mathrm{l})$ & 509 & 49 & & 478 & 45 & 0.497 \\
$t_{\max }(\mathrm{min})$ & 40 & 2 & & 38 & 1 & 0.839 \\
$c_{\min }(\mathrm{mmol} / \mathrm{l})$ & 74 & 4 & 67 & 3 & 0.263 \\
$t_{\min }(\mathrm{min})$ & 131 & 11 & 65 & 10 & 0.082 \\
$\mathrm{AUC}_{(0-120)}(\mathrm{mmol} / \mathrm{l} \times \mathrm{min})$ & 35 & 5 & 32 & 4 & 0.211 \\
$\mathrm{AUC}_{(0-240)}(\mathrm{mmol} / \mathrm{l} \times \min )$ & 55 & 7 & 51 & 6 & 0.305 \\
\hline
\end{tabular}

Fig. 3. Postprandial progression of (a) glucose and (b) insulin levels in the serum of male volunteers after ingestion of a high-energy meal in combination with a blackcurrant $(\mathrm{BC},-$ )-based juice or placebo (.......) beverage. Values are means of maximal and minimal plasma concentrations $\left(c_{\max }, c_{\min }\right)$, respective lag time $\left(t_{\max }, t_{\min }\right)$ and area under the curve $\left(\mathrm{AUC}_{0-120}, \mathrm{AUC}_{0-240}\right)$, with standard errors represented by vertical bars ( $n$ 11). * Mean values were significantly different $(P<0.05$; paired $t$ tests) for postprandial changes compared with baseline $(0 \mathrm{~min})$. 


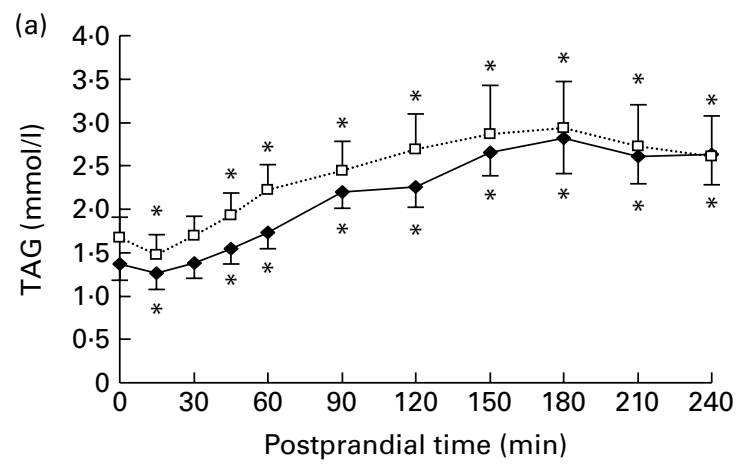

\begin{tabular}{lcccccc}
\hline & \multicolumn{3}{c}{ Blackcurrant } & & \multicolumn{3}{c}{ Placebo } & \\
\cline { 2 - 3 } & Mean & SEM & & Mean & SEM & $P$ \\
\hline$c_{\text {max }}(\mathrm{mmol} / \mathrm{l})$ & 3.3 & 0.3 & & 3.2 & 0.5 & 0.844 \\
$t_{\max }(\mathrm{min})$ & 171 & 5 & & 144 & 6 & 0.310 \\
$c_{\min }(\mathrm{mmol} / \mathrm{l})$ & 1.3 & 0.2 & 1.5 & 0.3 & 0.204 \\
$t_{\min }(\mathrm{min})$ & 14 & 2 & 18 & 2 & 0.177 \\
$\mathrm{AUC}_{(0-120)}(\mathrm{mmol} / \mathrm{l} \times \mathrm{min})$ & 183 & 19 & & 218 & 47 & 0.136 \\
AUC $_{(0-240)}(\mathrm{mmol} / / \times \mathrm{min})$ & 528 & 53 & 588 & 92 & 0.351 \\
\hline
\end{tabular}

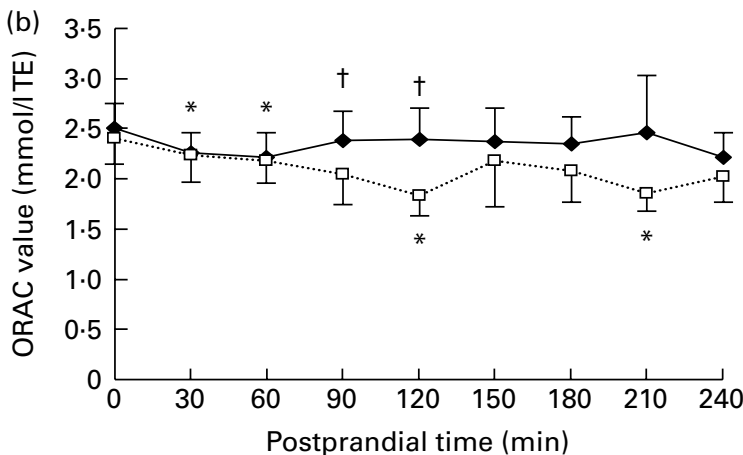

\begin{tabular}{|c|c|c|c|c|c|}
\hline & \multicolumn{2}{|c|}{$\underline{\text { Blackcurrant }}$} & \multicolumn{2}{|c|}{ Placebo } & \multirow[b]{2}{*}{$P$} \\
\hline & Mean & SEM & Mean & SEM & \\
\hline$c_{\max }(\mathrm{mmol} / \mathrm{l})$ & $3 \cdot 0$ & 0.5 & $2 \cdot 7$ & 0.4 & 0.205 \\
\hline$t_{\max }(\min )$ & 98 & 30 & 933 & 31 & 0.872 \\
\hline$c_{\min }(\mathrm{mmol} / \mathrm{l})$ & $1.9+$ & 0.2 & $1 \cdot 6$ & 0.2 & 0.012 \\
\hline$t_{\min }(\min )$ & 136 & 24 & 142 & 24 & 0.863 \\
\hline $\mathrm{AUC}_{(0-120)}(\mathrm{mmol} / \mathrm{I} \times \mathrm{min})$ & $279+$ & 27 & 257 & 25 & 0.006 \\
\hline $\mathrm{AUC}_{(0-240)}(\mathrm{mmol} / \mathrm{I} \times \mathrm{min})$ & $563+$ & 63 & 499 & 54 & 0.008 \\
\hline
\end{tabular}

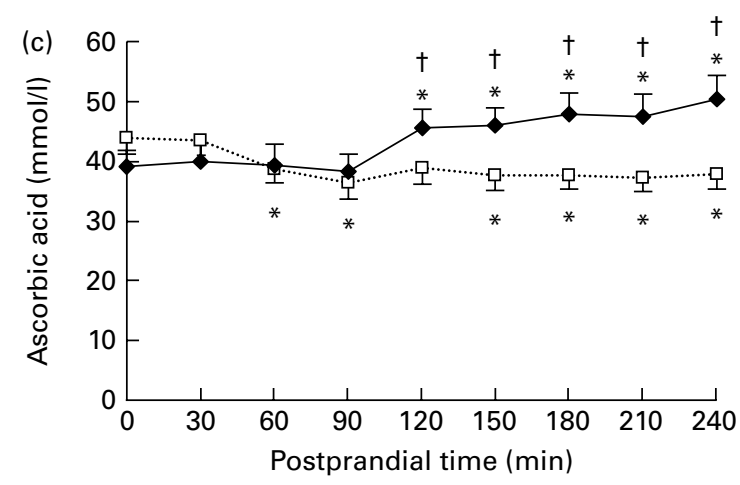

\begin{tabular}{lcccccc}
\hline & \multicolumn{3}{c}{ Blackcurrant } & & \multicolumn{3}{c}{ Placebo } & \\
\cline { 2 - 3 } & Mean & SEM & & Mean & SEM & $P$ \\
\hline$c_{\text {max }}(\mathrm{mmol} / \mathrm{l})$ & 53 & 4 & & 46 & 3 & 0.199 \\
$t_{\max }(\mathrm{min})$ & $173 \dagger$ & 23 & & 23 & 9 & 0.000 \\
$c_{\min }(\mathrm{mmol} / \mathrm{l})$ & 33 & 2 & 35 & 3 & 0.399 \\
$t_{\min }(\mathrm{min})$ & $65 \dagger$ & 20 & & 18 & 2 & 0.023 \\
$\mathrm{AUC}_{(0-120)}(\mathrm{mmol} / \mathrm{l} \times \mathrm{min})$ & 4802 & 283 & & 4798 & 332 & 0.988 \\
AUC $_{(0-240)}(\mathrm{mmol} / \mathrm{l} \times \mathrm{min})$ & $10484 \dagger$ & 705 & & 9329 & 575 & 0.037 \\
\hline
\end{tabular}

Fig. 4. Postprandial progression of (a) TAG, (b) oxygen radical-scavenging capacity (ORAC) and (c) ascorbic acid in the plasma of male volunteers after ingestion of a high-energy meal in combination with a blackcurrant (BC, - -based or placebo $(\cdots \cdots)$ beverage. Values are means of maximal and minimal plasma concentrations $\left(c_{\max }, c_{\min }\right)$, respective lag time $\left(t_{\max }, t_{\min }\right)$ and area under the curve $\left(\mathrm{AUC}_{0-120}, \mathrm{AUC}_{0-240}\right)$, with standard errors represented by vertical bars ( $n$ 10-11). ${ }^{*}$ Mean values were significantly different $(P<0.05$; paired $t$ tests) for postprandial changes compared with baseline (0 min). $\dagger$ Mean values were significantly different $(P<0.05$; paired $t$ tests $)$ between the BC $v$. placebo treatment. TE, Trolox equivalents.

significant, implying that the postprandial reduction of TNF- $\alpha$ and IL-1 $\beta$ secretion was attenuated compared with placebo. Postprandial TNF- $\alpha$ levels were significantly lower in the placebo than in the $\mathrm{BC}$ treatment group $(P<0 \cdot 001)$. Furthermore, circulating IL-6 was measured in plasma at 0, 120 and $240 \mathrm{~min}$ following ingestion of the test meals. Interestingly, postprandial IL-6 mean values were increased in the $\mathrm{BC}$ group from $2.74(\operatorname{sem} 0.43) \mathrm{pg} / \mathrm{ml}$ to $3 \cdot 24$ (SEM 0.41$) \mathrm{pg} / \mathrm{ml}$ $(P=0.385)$ and $5.03($ SEM 0.81$) \mathrm{pg} / \mathrm{ml}(P=0.009)$ after 120 and $240 \mathrm{~min}$, respectively, whereas mean values in the placebo group were increased after $120 \mathrm{~min}$ from 3.58 (SEM $0 \cdot 56)$ to $4.48(\operatorname{sem} 0.85) \mathrm{pg} / \mathrm{ml}(P=0.330)$, but then decreased 
Table 5. Postprandial changes in total cholesterol (TC), LDL- and HDL-cholesterol, oxidised LDL (oxLDL), $\alpha$-tocopherol, paraoxonase (PON) activity, TNF- $\alpha$ and IL- $1 \beta$ of male volunteers after ingestion of a high-energy meal in combination with a blackcurrant (BC)-based or placebo beverage (placebo) (Mean values with their standard errors)

\begin{tabular}{|c|c|c|c|c|c|c|c|c|c|c|c|c|}
\hline & \multicolumn{5}{|c|}{$\mathrm{BC}$} & \multicolumn{5}{|c|}{ Placebo } & & \\
\hline & \multicolumn{2}{|c|}{$0 \min$} & \multicolumn{2}{|c|}{$240 \min$} & \multirow[b]{2}{*}{$P$ (time) $\dagger$} & \multicolumn{2}{|c|}{$0 \min$} & \multicolumn{2}{|c|}{$240 \mathrm{~min}$} & \multirow[b]{2}{*}{$P$ (time) $\dagger$} & \multicolumn{2}{|c|}{$P{\text { (treatment })^{\star}}^{\star}$} \\
\hline & Mean & SEM & Mean & SEM & & Mean & SEM & Mean & SEM & & $0 \mathrm{~min}$ & $240 \mathrm{~min}$ \\
\hline $\mathrm{TC}(\mathrm{mmol} / \mathrm{l}) \ddagger$ & 5.99 & 0.31 & $5 \cdot 76 \dagger$ & 0.27 & 0.012 & 6.08 & 0.33 & $5 \cdot 78 \dagger$ & 0.28 & 0.009 & 0.569 & 0.856 \\
\hline LDL $(\mathrm{mmol} / \mathrm{l}) \ddagger$ & 4.02 & 0.25 & $3.77 \dagger$ & 0.23 & 0.000 & 4.07 & 0.25 & $3.76 \dagger$ & 0.21 & 0.000 & 0.780 & 0.969 \\
\hline $\mathrm{HDL}(\mathrm{mmol} / \mathrm{l}) \ddagger$ & 1.08 & 0.08 & $1.00 \dagger$ & 0.07 & 0.016 & $1 \cdot 10$ & 0.07 & $0.99 \dagger$ & 0.06 & 0.003 & 0.601 & 0.683 \\
\hline $\operatorname{oxLDL}(\mathrm{U} / \mathrm{ml}) \ddagger$ & $72 \cdot 9$ & $3 \cdot 6$ & 71.4 & $3 \cdot 7$ & 0.625 & $75 \cdot 3$ & $2 \cdot 5$ & $70 \cdot 9$ & 3.5 & 0.140 & 0.370 & 0.911 \\
\hline$\alpha$-Tocopherol $(\mu \mathrm{mol} / \mathrm{l}) \ddagger$ & $35 \cdot 1$ & 7.4 & $27 \cdot 0$ & $2 \cdot 3$ & 0.321 & 33.2 & $4 \cdot 1$ & 29.7 & $3 \cdot 1$ & 0.300 & 0.758 & 0.295 \\
\hline PON (kU/mmol HDL)‡ & 95.8 & $10 \cdot 6$ & $106 \cdot 2$ & 13.2 & 0.254 & 98.2 & 8.7 & $103 \cdot 2$ & $10 \cdot 6$ & 0.402 & 0.192 & 0.654 \\
\hline TNF- $\alpha(\mathrm{ng} / \mathrm{ml}) \S$ & 0.81 & 0.15 & 0.73 & $0 \cdot 10$ & 0.238 & 0.68 & 0.10 & $0.58^{*} \dagger$ & 0.08 & 0.006 & 0.268 & 0.000 \\
\hline $\mathrm{IL}-1 \beta(\mathrm{ng} / \mathrm{ml}) \S$ & 1.25 & 0.09 & $1 \cdot 17$ & 0.09 & 0.076 & 1.24 & 0.08 & $1.14 \dagger$ & 0.09 & 0.047 & 0.842 & 0.357 \\
\hline
\end{tabular}

${ }^{*}$ Mean values of BC were significantly different from those of placebo treatment $(P<0.05$; paired $t$ test).

$\dagger$ Mean values at 0 min were significantly different from those of $240 \mathrm{~min}(P<0.05$; paired $t$ test).

$\ddagger$ Concentrations of TC, LDL-cholesterol, HDL-cholesterol, oxLDL, $\alpha$-tocopherol and PON activity were determined in plasma.

$\S \mathrm{TNF}-\alpha$ and IL-1 $\beta$ production was measured in ex vivo stimulated whole-blood cultures before $(0 \mathrm{~min})$ and after $(240 \mathrm{~min})$ the test meal.

after $240 \mathrm{~min}$ to $3.92(\operatorname{sem} 0.84) \mathrm{pg} / \mathrm{ml}(P=0 \cdot 285)$. Plasma IL-6 levels were not significantly different when comparing the treatment groups (Fig. 5).

\section{Discussion}

Fruit and vegetables may reduce the risk of CVD partly due to their high content of polyphenolic and other bioactive compounds. However, experimental evidence is limited, especially concerning the potential health benefits of fruits and fruit juices in the postprandial state. Postprandial increases in insulin, glucose and particularly TAG may induce oxidative and inflammatory stress, particularly in obese and diabetic subjects $^{(12,14,25,26)}$. Postprandial hyperglycerolaemia is associated with enhanced plasma levels of pro-inflammatory cytokines such as TNF- $\alpha$ and IL- $6^{(27-29)}$, and the magnitude of postprandial TAG accumulation is considered to be an independent risk factor for atherosclerosis ${ }^{(30,31)}$. In the present study, we compared the in vitro with the in vivo anti-inflammatory properties of $\mathrm{BC}$, chosen due to its high concentration of both polyphenols and ascorbic acid.

In our cultured macrophages, the BC treatment significantly inhibited LPS-induced inflammation indicated by lower mRNA levels of TNF- $\alpha$, IL- $1 \beta$ and iNOS. Reduced expression of these cytokines may be attributable to the reduced activation of NF-кB since we observed lower nuclear p65 levels in BC-treated cells. Furthermore, CD36 mRNA and intracellular cholesterol were lower in BC-treated cells, suggesting reduced scavenger receptor-mediated cholesterol accumulation in activated macrophages. Taken together, our data indicate that $\mathrm{BC}$ potentially attenuates macrophage activation in vitro, thereby counteracting chronic inflammatory processes associated with atherosclerosis $^{(32)}$. Therefore, we developed a smoothie containing BC and other fruits which exhibited antioxidant and anti-inflammatory properties in vitro for the human intervention study. In order to meet wide consumer acceptance, a sensory panel evaluated different smoothie recipes in terms of sweetness and bitterness, texture, astringency, etc. The final smoothie recipe contained the highest feasible concentration of BC purée of $15 \%$, besides red grape, raspberry and cherry fruit juices and purées. In the present in vitro analyses, these fruits were shown to have relatively high amounts of phenolic compounds and ascorbic acid and to exhibit antioxidative or anti-inflammatory properties. Since within the scope of the present study our primary concern was to evaluate potential in vivo effects, we focused on the presentation of in vitro data on BC.

For the present human pilot intervention study, we recruited men with an atherosclerosis-prone phenotype (including BMI $>25 \mathrm{~kg} / \mathrm{m}^{2}$ and TAG $>1.7 \mathrm{mmol} / \mathrm{l}$ ) and evaluated the effects of a BC-based beverage (smoothie) on the postprandial progression of blood biomarkers after a highfat and high-carbohydrate meal. Plasma TAG, glucose and insulin were increased in our subjects after the high-energy meal, while no significant differences were observed between the $\mathrm{BC}$ and placebo time curves. Nevertheless, TAG tended to be lower following the $\mathrm{BC}$ treatment compared with placebo. This may be of particular importance as the magnitude of postprandial TAG is related to CVD risk ${ }^{(27)}$. Follow-up studies including higher numbers of subjects are warranted to verify

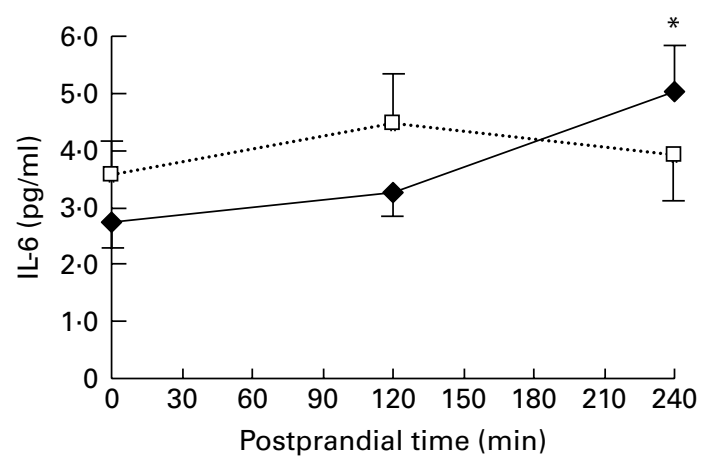

Fig. 5. Circulating IL-6 concentration in the plasma of male volunteers before $(0 \mathrm{~min})$ and after $(120,240 \mathrm{~min})$ ingestion of a high-energy meal in combination with a blackcurrant $(\mathrm{BC},-$ )-based or placebo $(\cdots \oplus \cdot$.$) beverage.$ Values are means, with standard errors represented by vertical bars ( $n 10)$. ${ }^{*}$ Mean values were significantly different $(P<0.05$; paired $t$ tests) for postprandial changes compared with baseline $(0 \mathrm{~min})$. 
the trend of lower postprandial TAG levels in response to BC consumption observed in the present study.

In our subjects, total cholesterol, HDL- and LDL-cholesterol were significantly decreased in response to the high-fat and carbohydrate meal, an effect that has recently been described in the literature ${ }^{(33,34)}$. Despite the relatively small number of participants in the present study, we were able to confirm the significant postprandial decline in total cholesterol and LDL-cholesterol of about $0 \cdot 2-0 \cdot 3 \mathrm{mmol} / 1$ and HDL-cholesterol of about $0 \cdot 1 \mathrm{mmol} / \mathrm{l}$. There may be two possible explanations for this postprandial decline in cholesterol: increased liver uptake and increased transport of LDL particles from plasma into the arterial wall ${ }^{(33)}$. The latter would promote atherosclerotic events and contribute to the proatherogenic phenotype occurring during the postprandial state. However, no differences in cholesterol levels were observed between the $\mathrm{BC}$ and placebo treatments.

Increased low-grade inflammation mainly related to higher circulating levels of pro-inflammatory cytokines is supposed to contribute to the postprandial proatherogenic phenotype. Indeed, meal-induced TAG has been shown to activate leucocytes and inflammatory signalling pathways, such as $\mathrm{NF}-\kappa^{(35,36)}$. Nevertheless, several lines of evidence also suggest a postprandial decrease in circulating TNF- $\alpha$ levels ${ }^{(37,38)}$. In the present study, TNF- $\alpha$ and IL-1 $\beta$ were measured in supernatants of ex vivo stimulated whole-blood cell cultures and were thus mainly related to leucocytemediated inflammation. Both TNF- $\alpha$ and IL- $1 \beta$ were significantly reduced following the consumption of the placebo test meal. Interestingly, after the $\mathrm{BC}$ test meal, TNF- $\alpha$ and IL-1 $\beta$ were also decreased but to a lower extent, which was not significantly different from baseline. This may indicate that the TNF- $\alpha$-lowering effect elicited by the high-energy meal was attenuated by BC consumption.

In addition, circulating levels of IL- 6 were determined in plasma. The role of circulating IL- 6 has been controversially discussed with special regard to insulin sensitivity ${ }^{(39,40)}$. IL-6 may be able to suppress other pro-inflammatory, mainly adipocyte-derived cytokines, induce lipolysis and increase glucose uptake ${ }^{(41,42)}$. Lack of functional IL-6 is associated with impaired glucose tolerance and hyperglycerolaemia ${ }^{(39,43)}$. Therefore, short-term increases in circulating IL-6 levels such as during the postprandial state have been suggested to be beneficial ${ }^{(44)}$. In the present study, plasma IL-6 was significantly increased after the BC but not after the placebo test meal. However, the role of postprandial circulating pro-inflammatory cytokines is still uncertain and warrants further investigations.

We furthermore examined plasma radical-scavenging capacity (ORAC) and ascorbic acid concentrations in our subjects following test meal consumption. We observed a significant reduction in both parameters in the placebo group, indicative of an oxidative imbalance in the postprandial state. After BC meal consumption, postprandial ORAC values were likewise decreased (at 30 and $60 \mathrm{~min}$ ), but increased significantly again after 90 and $120 \mathrm{~min}$. This may be a result of intestinal absorption of ascorbic acid present in high concentrations in the $\mathrm{BC}$ beverage. In accordance, plasma ascorbic acid concentrations were significantly higher after BC meal consumption compared with both baseline and placebo meal consumption. Since the increases in plasma ascorbic acid and in ORAC values do not exactly coincide (120 v. $90 \mathrm{~min}$ ), endogenous mechanisms, which modulate the postprandial antioxidant/oxidant balance or dietary factors such as other BC meal-derived compounds, may have contributed to increased plasma radical-scavenging capacity. As such, plasma anthocyanin and anthocyanin metabolites were analysed; however, none was detectable. This may be due to the relatively low bioavailability of anthocyanins that has been already described in the literature ${ }^{(15)}$. In a previous study, the intake of $183 \mathrm{mg}$ anthocyanins resulted in a plasma concentration of only $4 \mathrm{nmol} / \mathrm{l}^{(45)}$. Since the anthocyanin concentration of the $\mathrm{BC}$ juice used in the present study was $11 \mathrm{mg}$, we assume that the plasma anthocyanin levels did not exceed $1 \mathrm{nmol} / 1$, which was the detection limit of the method used. We did, however, find increased amounts of the predicted gut-derived flavonoid metabolite, 1,3,5-trihydroxybenzene, in plasma 90-120 min postprandially, indicating the absorption of possible anthocyanin breakdown products.

Nevertheless, the value of determining radical-scavenging capacity by the ORAC and other related assays may be limited to assess antioxidant power in vivo ${ }^{(46)}$. Furthermore, it has also been partly questioned whether antioxidants actually contribute to the beneficial effects of fruit and vegetables per $s e^{(47)}$. Interestingly, in our volunteers, postprandial levels of oxLDL were not different from baseline and also not different between the placebo and BC groups. The activity of paraoxonase, which prevents and reverses LDL oxidation in plasma, was also not different in response to the test meals and between the treatments. As a consequence, we may assume that our subjects were, by and large, not exposed to increased oxidative stress (as indicated by oxLDL) in the postprandial state.

Taken together, BC juice exhibited potent anti-inflammatory properties in cultured macrophages in vitro, probably owing to its high polyphenol and ascorbic acid concentrations. In human subjects, consumption of a BC-based juice counteracted the decrease in plasma radical-scavenging capacity and significantly increased plasma ascorbic acid following a high-fat and -carbohydrate meal. Though effects on the postprandial pro-inflammatory response were not clear, TAG may be attenuated by BC-based juice consumption. Overall, the potential anti-atherogenic effects observed in vitro cannot be directly transferred to the postprandial situation in vivo, at least partly, due to the very low bioavailability of anthocyanins.

\section{Acknowledgements}

We thank all the volunteers for their time. This study was financially supported by Innovationsstiftung SchleswigHolstein, Kiel, Germany (grant no. 2007-27H). P. H. and G. R. designed the study. K. G. conducted the cell-culture experiments. P. H., A. A. and C. N. A. conducted the human study. S. d. P.-T. performed the anthocyanidin analysis. 
B. A. and S. P. developed the BC-based and placebo beverages. P. H. and G. R. wrote the manuscript. All authors read and approved the final manuscript. P. H., K. G., S. d. P.-T. and G. R. declare conflict of interests. B. A. and S. P. are employed by Schwartauer Werke. A. A. and C. N. A. are members of the Health Centre at Duck Pond. The manuscript is dedicated to Dr Cord Arkenau senior, founding member of the Health Centre at Duck Pond.

\section{References}

1. Goldstein JL, Ho YK, Basu SK, et al. (1979) Binding site on macrophages that mediates uptake and degradation of acetylated low density lipoprotein, producing massive cholesterol deposition. Proc Natl Acad Sci US A 76, 333-337.

2. Poston RN \& Davies DF (1974) Immunity and inflammation in the pathogenesis of atherosclerosis. A review. Atherosclerosis 19, 353-367.

3. Ness AR \& Powles JW (1997) Fruit and vegetables, and cardiovascular disease: a review. Int J Epidemiol 26, 1-13.

4. Liu S, Manson JE, Lee IM, et al. (2000) Fruit and vegetable intake and risk of cardiovascular disease: the Women's Health Study. Am J Clin Nutr 72, 922-928.

5. He FJ, Nowson CA, Lucas M, et al. (2007) Increased consumption of fruit and vegetables is related to a reduced risk of coronary heart disease: meta-analysis of cohort studies. J Hum Hypertens 21, 717-728.

6. Dauchet L, Amouyel P, Hercberg S, et al. (2006) Fruit and vegetable consumption and risk of coronary heart disease: a meta-analysis of cohort studies. J Nutr 136, 2588-2593.

7. Garcia-Alonso M, Rimbach G, Rivas-Gonzalo JC, et al. (2004) Antioxidant and cellular activities of anthocyanins and their corresponding vitisins A - studies in platelets, monocytes, and human endothelial cells. J Agric Food Chem 52, 3378-3384.

8. Garcia-Alonso M, Rimbach G, Sasai M, et al. (2005) Electron spin resonance spectroscopy studies on the free radical scavenging activity of wine anthocyanins and pyranoanthocyanins. Mol Nutr Food Res 49, 1112-1119.

9. Aviram M, Dornfeld L, Rosenblat M, et al. (2000) Pomegranate juice consumption reduces oxidative stress, atherogenic modifications to LDL, and platelet aggregation: studies in humans and in atherosclerotic apolipoprotein E-deficient mice. Am J Clin Nutr 71, 1062-1076.

10. Norata GD, Marchesi P, Passamonti S, et al. (2007) Antiinflammatory and anti-atherogenic effects of cathechin, caffeic acid and trans-resveratrol in apolipoprotein $\mathrm{E}$ deficient mice. Atherosclerosis 191, 265-271.

11. Miyazaki K, Makino K, Iwadate E, et al. (2008) Anthocyanins from purple sweet potato Ipomoea batatas cultivar Ayamurasaki suppress the development of atherosclerotic lesions and both enhancements of oxidative stress and soluble vascular cell adhesion molecule-1 in apolipoprotein E-deficient mice. J Agric Food Chem 56, 11485-11492.

12. O'Keefe JH, Gheewala NM \& O'Keefe JO (2008) Dietary strategies for improving post-prandial glucose, lipids, inflammation, and cardiovascular health. J Am Coll Cardiol 51, $249-255$.

13. Ghanim H, Sia CL, Upadhyay M, et al. (2010) Orange juice neutralizes the proinflammatory effect of a high-fat, highcarbohydrate meal and prevents endotoxin increase and Toll-like receptor expression. Am J Clin Nutr 91, 940-949.

14. Burton-Freeman B, Linares A, Hyson D, et al. (2010) Strawberry modulates LDL oxidation and postprandial lipemia in response to high-fat meal in overweight hyperlipidemic men and women. J Am Coll Nutr 29, 46-54.

15. Bub A, Watzl B, Heeb D, et al. (2001) Malvidin-3-glucoside bioavailability in humans after ingestion of red wine, dealcoholized red wine and red grape juice. Eur J Nutr $\mathbf{4 0}$, 113-120.

16. Weisel T, Baum M, Eisenbrand G, et al. (2006) An anthocyanin/polyphenolic-rich fruit juice reduces oxidative DNA damage and increases glutathione level in healthy probands. Biotechnol J 1, 388-397.

17. Cao G, Alessio HM \& Cutler RG (1993) Oxygen-radical absorbance capacity assay for antioxidants. Free Radic Biol Med 14, 303-311.

18. Gaedicke S, Zhang X, Schmelzer C, et al. (2008) Vitamin E dependent microRNA regulation in rat liver. FEBS Lett $\mathbf{5 8 2}$, 3542-3546.

19. Wagner AE, Ernst I, Iori R, et al. (2010) Sulforaphane but not ascorbigen, indole-3-carbinole and ascorbic acid activates the transcription factor Nrf2 and induces phase-2 and antioxidant enzymes in human keratinocytes in culture. Exp Dermatol 19, 137-144.

20. Boesch-Saadatmandi C, Egert S, Schrader C, et al. (2010) Effect of quercetin on paraoxonase 1 activity-studies in cultured cells, mice and humans. J Physiol Pharmacol 61, 99-105.

21. Boesch-Saadatmandi C, Rimbach G, Schrader C, et al. (2010) Determinants of paraoxonase activity in healthy adults. Mol Nutr Food Res 54, 1842-1850.

22. Vitaglione P, Donnarumma G, Napolitano A, et al. (2007) Protocatechuic acid is the major human metabolite of cyanidin-glucosides. J Nutr 137, 2043-2048.

23. Nurmi T, Mursu J, Heinonen M, et al. (2009) Metabolism of berry anthocyanins to phenolic acids in humans. I Agric Food Chem 57, 2274-2281.

24. Coldham NG, Darby C, Hows M, et al. (2002) Comparative metabolism of genistin by human and rat gut microflora: detection and identification of the end-products of metabolism. Xenobiotica 32, 45-62.

25. Aljada A, Mohanty P, Ghanim H, et al. (2004) Increase in intranuclear nuclear factor kappaB and decrease in inhibitor kappaB in mononuclear cells after a mixed meal: evidence for a proinflammatory effect. Am J Clin Nutr 79, 682-690.

26. Esposito K, Nappo F, Marfella R, et al. (2002) Inflammatory cytokine concentrations are acutely increased by hyperglycemia in humans: role of oxidative stress. Circulation 106, 2067-2072.

27. Burdge GC \& Calder PC (2005) Plasma cytokine response during the postprandial period: a potential causal process in vascular disease? Br J Nutr 93, 3-9.

28. Nappo F, Esposito K, Cioffi M, et al. (2002) Postprandial endothelial activation in healthy subjects and in type 2 diabetic patients: role of fat and carbohydrate meals. $J \mathrm{Am}$ Coll Cardiol 39, 1145-1150.

29. Lundman P, Boquist S, Samnegard A, et al. (2007) A high-fat meal is accompanied by increased plasma interleukin- 6 concentrations. Nutr Metab Cardiovasc Dis 17, 195-202.

30. Patsch JR, Miesenbock G, Hopferwieser T, et al. (1992) Relation of triglyceride metabolism and coronary artery disease. Studies in the postprandial state. Arterioscler Thromb 12, 1336-1345.

31. Ebenbichler CF, Kirchmair R, Egger C, et al. (1995) Postprandial state and atherosclerosis. Curr Opin Lipidol 6, 286-290.

32. Berliner JA, Navab M, Fogelman AM, et al. (1995) Atherosclerosis: basic mechanisms. Oxidation, inflammation, and genetics. Circulation 91, 2488-2496. 
33. Lund SS, Petersen M, Frandsen M, et al. (2008) Sustained postprandial decrease in plasma levels of LDL cholesterol in patients with type-2 diabetes mellitus. Scand J Clin Lab Invest 68, 628-640.

34. Hartwich J, Leszczynska-Golabek I, Kiec-Wilk B, et al. (2010) Lipoprotein profile, plasma ischemia modified albumin and LDL density change in the course of postprandial lipemia. Insights from the LIPGENE study. Scand J Clin Lab Invest 70, 201-208.

35. Bellido C, Lopez-Miranda J, Blanco-Colio LM, et al. (2004) Butter and walnuts, but not olive oil, elicit postprandial activation of nuclear transcription factor kappaB in peripheral blood mononuclear cells from healthy men. Am J Clin Nutr 80, 1487-1491.

36. van Oostrom AJ, Rabelink TJ, Verseyden C, et al. (2004) Activation of leukocytes by postprandial lipemia in healthy volunteers. Atherosclerosis 177, 175-182.

37. Blackburn P, Despres JP, Lamarche B, et al. (2006) Postprandial variations of plasma inflammatory markers in abdominally obese men. Obesity (Silver Spring) 14, 1747-1754.

38. Payette C, Blackburn P, Lamarche B, et al. (2009) Sex differences in postprandial plasma tumor necrosis factor-alpha, interleukin- 6 , and C-reactive protein concentrations. Metabolism 58, 1593-1601.

39. Pedersen BK \& Febbraio MA (2007) Point: interleukin-6 does have a beneficial role in insulin sensitivity and glucose homeostasis. J Appl Physiol 102, 814-816.
40. Mooney RA (2007) Counterpoint: interleukin-6 does not have a beneficial role in insulin sensitivity and glucose homeostasis. J Appl Physiol 102, 816-818, discussion 818-819.

41. Petersen AM \& Pedersen BK (2005) The anti-inflammatory effect of exercise. J Appl Physiol 98, 1154-1162.

42. Carey AL, Steinberg GR, Macaulay SL, et al. (2006) Interleukin-6 increases insulin-stimulated glucose disposal in humans and glucose uptake and fatty acid oxidation in vitro via AMP-activated protein kinase. Diabetes 55, $2688-2697$.

43. Wallenius V, Wallenius $\mathrm{K}$, Ahren $\mathrm{B}$, et al. (2002) Interleukin6-deficient mice develop mature-onset obesity. Nat Med $\mathbf{8}$, 75-79.

44. Nieto-Vazquez I, Fernandez-Veledo S, de Alvaro C, et al. (2008) Dual role of interleukin-6 in regulating insulin sensitivity in murine skeletal muscle. Diabetes $\mathbf{5 7}$, 3211-3221.

45. Garcia-Alonso M, Minihane AM, Rimbach G, et al. (2009) Red wine anthocyanins are rapidly absorbed in humans and affect monocyte chemoattractant protein 1 levels and antioxidant capacity of plasma. J Nutr Biochem 20, 521-529.

46. Niki E (2010) Assessment of antioxidant capacity in vitro and in vivo. Free Radic Biol Med 49, 503-515.

47. Gutteridge JM \& Halliwell B (2010) Antioxidants: molecules, medicines, and myths. Biochem Biophys Res Commun 393, $561-564$. 